\title{
Aesthetic Experience and Creativity in Interactive Art
}

\author{
Esma Betül Savaş, ${ }^{1, *}$, Thijs Verwijmeren ${ }^{1}$ and Rob van Lier ${ }^{2}$ \\ ${ }^{1}$ Radboud University, Behavioural Science Institute, Thomas van Aquinostraat 4, 6525 GD \\ Nijmegen, The Netherlands \\ ${ }^{2}$ Radboud University, Donders Institute for Brain, Cognition and Behaviour, Heyendaalseweg \\ 135, 6525 AJ Nijmegen, The Netherlands
}

Received 22 September 2020; accepted 17 March 2021

\begin{abstract}
Interactive art, which is art that relies on the participation of a spectator and in which the spectators enter the creative process, has changed the way people relate with artworks. An experiment was conducted in a laboratory with an interactive artwork (Temporal Perspectives by Doruk Kumkuoğlu and Sadettin Bilal Savaş, 2016) to investigate whether interactivity is a factor that plays a role in the aesthetic emotions and creativity of the spectator. The results indicated a significant increase in beauty, in response to interactive art. Partial correlational network analyses were conducted to further investigate the emotional experience of the artworks in both conditions. These analyses showed differences between the conditions in the emotional response to interactive art. However, cognitive flexibility of participants did not differ between conditions. The results indicate that interactivity should be taken into account as an element that affects the perception of art.
\end{abstract}

\section{Keywords}

Aesthetic emotions, creativity, empirical aesthetics, interactive art

\section{Introduction}

"You use a glass mirror to see your face; you use works of art to see your soul."
George Bernard Shaw

\footnotetext{
* To whom correspondence should be addressed. E-mail: e.betulsavas@ gmail.com 
Art has the power to inspire and transform its spectator's life. It has been celebrated for evoking 'unusual' emotions for thousands of years. This transformative experience one goes through while encountering an artwork, called the aesthetic experience, has boggled minds of many great thinkers. Kant (1790) associated aesthetic experience with the pleasure you associate with something beautiful; Dewey (1958) regarded it as the most complete, the richest and the highest experience possible; Goodman (1976) argued that art leads to perceiving the world through the work by feeling emotions, whether positive or negative, pleasant or unpleasant. Even though there are different ways to explain the phenomenon, researchers agree that it involves cognitive and affective processes. Some researchers who focus on the affective side argue that emotions shape the aesthetic experience (Menninghaus et al., 2019), and thus consider emotions as the strongest predictors of art appreciation (Leder et al., 2012). While investigating emotions does not provide us with the whole picture, they help us to get close to what a spectator experiences while viewing an artwork.

People experience different sets of emotions every day; we get angry, happy, sad when we encounter events. In addition to these emotions that we feel regularly, one can also experience emotions such as beauty, fascination, awe when encountering, for example, an artwork. Scherer (2005) argues that these emotions, what he also calls aesthetic emotions, are produced by the appreciation of the intrinsic qualities of the beauty of nature, or the qualities of a work of art or an artistic performance. Schindler and colleagues (2017) make use of this distinction to categorise being moved, surprise, fascination, feeling of beauty, and awe under the latent variable of Prototypical Aesthetic Emotions (PAE) in a questionnaire that tests emotions during an aesthetic experience. Previous research has shown that the positive emotional output elicited from the aesthetic experience affects mood, and indirectly promotes health and well-being (Mastandrea et al., 2019). Likewise, Cuypers and colleagues (2012) show that there is an association between taking part in cultural activities such as going to museums and higher satisfaction in life. Other instances of art enhancing well-being can be seen in the area of art therapy, in which individuals, including older adults, veterans and prison inmates, have been shown to benefit from art therapy (Maujean et al., 2014). Considering that being involved with art has numerous outcomes, it is important to investigate components that affect aesthetic experience.

Experiencing art is a complex phenomenon. This complexity is due to several factors that play a role in aesthetic appreciation and can be associated with the spectator, the environment, and the artwork. For example, a higher level of art expertise of the spectator is related to having a higher appreciation of an artwork compared to an unexperienced viewer (Leder et al., 2012; Pihko et al., 2011). In addition, the environment in which the art experience takes place has 
been shown to be crucial as researchers found that viewing a painting in the museum increases emotions and liking in comparison to viewing it on a computer in a laboratory (Carbon, 2019). Moreover, some properties of an artwork, such as its complexity (Muth et al., 2015) or its novelty (Berlyne, 1970) are argued to affect the appreciation of art. Different types of artworks elicit different emotional reactions (Uusitalo et al., 2012). For example, when Uusitalo and colleagues (2012) compared representational art to abstract art, they found that participants had lower emotional reactions to abstract art than to representational art. However, one common feature of the types of artwork that are investigated is that they are consumed inertly by the viewer. In contrast, there are relatively new types of art, namely interactive art, that depend on the active participation of the spectator. Interactive art is a type of art that challenges the way art is produced and perceived by giving the spectator a creative role during the viewing of the artwork. While in other artworks the spectator might be affected by the artwork, in interactive art, the artwork is also affected by the spectator. As this allows for a quite different art experience, we aim, in the current study, to examine how an interactive art experience influences aesthetic experience, and more specifically, emotions.

\subsection{Interactive Art}

The idea of actively including the viewer in artworks became popular in the 20 th century with the rise of electronics. One of the most important components of interactive art is that it uses the space and the viewer input to become an artwork. Thus, the creation process not only consists of the artist's creativity, but also of the collaboration between the artist and the spectator. The interaction can differ largely depending on the artwork; it can be three-dimensional or dependent on the internet, it can create sound or movement, etc. As a result of this interaction the artwork will respond to the spectator. Thus, the artwork receives form and meaning by the participation of the spectator. An example of an interactive artwork is Chris Milk's The Treachery of Sanctuary (2012, https://www.youtube.com/watch?v=I5_9hq-yas\&t=2s). The artwork consists of three panels of screens that appear white until a spectator enters the exhibition space. Once the spectator is in front of the first panel (representing birth), the body is shadowed into the screen with an attachment of wings onto it. The spectator controls the movements of the wings in the panel by moving their arms. The experience continues with the spectator moving to the other panels that represent death and life.

The experience for the spectator of an interactive artwork might be different than for other kinds of art. Remarkably, there is a lack of research on how interactivity affects the aesthetic experience. Previous research alludes to certain elements of interactivity, such as movement, being a crucial part of the 
aesthetic experience (Brinck, 2018). Brinck (2018, p. 209) argues in her paper that "the more invitations to interact from artworks that a viewer responds to and the more ways of responding she masters, the more she will learn about her real possibilities to explore art visually and her ability to control the process". Whereas moving through the exhibition space has been associated with affecting aesthetic experience in representational art, the leap from representational to interactive art has yet to be made. As interactive art in itself invites people to act in order to explore the artwork further, it would be plausible that this influences their aesthetic experience. Notably, having control over the artwork might also have an effect on their experience. Thus, our first aim with this project is to take the leap and investigate how interactivity affects viewers' aesthetic emotions in interactive art.

Art is not only associated with having an aesthetic experience, but also with inspiration and creativity. We often see artists as the creative minds of our society. However, whether viewing art makes people creative is a question that does not have a simple answer. Recent research has shown that appreciating art induces inspiration, which in turn facilitates performance on creative tasks (An and Youn, 2017). One of the explanations of the higher performance on creative tasks could be that art viewers experience a schema violation when confronted with an artwork. People experience schema violations when a well-known sequence of events is interrupted by something unexpected. These violations enhance cognitive flexibility and creative thinking (Ritter et al., 2012, 2014). Ritter and colleagues (2014) show that having diversifying experiences leads to having one's schemas violated, which in turn leads to improvement of cognitive flexibility. The improvement of cognitive flexibility, which is the ability to break old patterns, can in turn allow someone to make creative associations between concepts (Guildford, 1967). In our study, we argue that an encounter with an interactive artwork might lead to more schema violations than an encounter with an artwork that is not interactive. A usual encounter with a non-interactive artwork consists of standing in front of it, maybe moving a bit closer to see the details, then moving back again to view it as a whole. In this usual encounter, the spectator responds in a certain way to the artwork. However, with interactive art, this schema of art perception is violated by the necessity of bodily and mental participation from the spectator. The spectator needs to understand that the artwork is in need of input, thus giving input according to their choice. Thus, their schemas may be violated because they not only respond to the artwork, but the artwork also responds to them. This schema violation in turn can trigger inspiration and creativity. Thus, the second goal of our project is to see whether interactive art has an effect on creativity.

Thus, we conducted an experiment in a controlled setting with no environmental distractions to have fewer confounding variables. In this experiment, 
participants encountered an artwork in an interactive or non-interactive way, after which they reported their emotional reactions. We hypothesized that participants who encounter an interactive artwork will have a higher intensity of PAE (being moved, surprise, fascination, feeling of beauty, and awe) than participants who encounter the non-interactive version, as actors will be more emotionally involved in the experience. Our second hypothesis was that participants in the interactive condition will have higher cognitive flexibility than participants in the non-interactive condition as the interactive artwork is more schema-violating than the non-interactive artwork. The study incorporated several other measures exploratively as interactive art has not been experimentally investigated before.

\section{Method}

\subsection{The Artwork}

The artwork, Temporal Perspectives by Doruk Kumkuoğlu and Sadettin Bilal Savaş (2016, Fig. 1), is a digital interactive artwork that follows the viewer's body movements with Kinect v2, allowing the viewer to activate the image on the projector screen by moving parallel to the screen (i.e., left-right) and moving perpendicular to the screen (i.e., forward-backward) in a $12 \mathrm{~m}^{2}$ space. It was originally exhibited in the 2016 Akbank Sanat Exhibition in

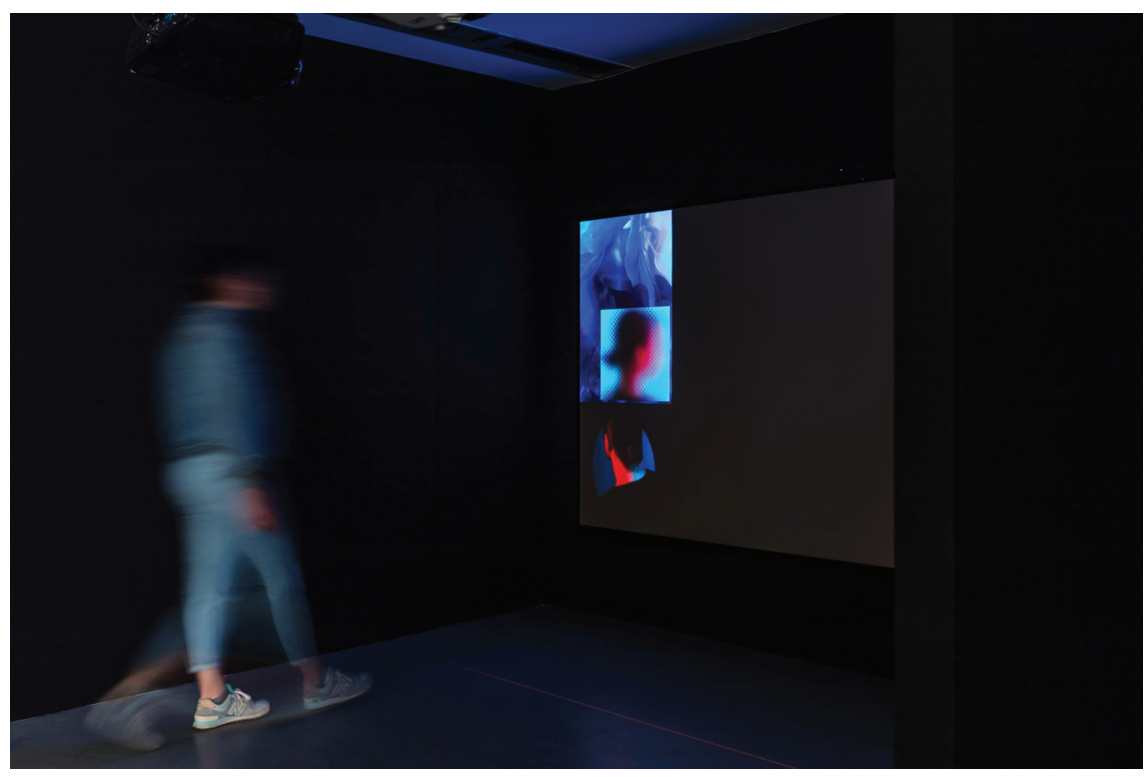

Figure 1. The artwork Temporal Perspectives by Doruk Kumkuoğlu and Sadettin Bilal Savaş (2016). 
Istanbul. The artwork consists of 165 photographs, which are shown in five different columns at different points of the interaction. The coding of the artwork was built with the Processing software in such a way that each column is activated by moving left to right, and different types of photographs in each column are activated by moving forward and backward. For example, the photographs of a person would get more detailed as you move closer to the screen or get less detailed as you move further away. In the lab, the artwork was projected onto two projector screens via a long-throw projector with a resolution of $1900 \times 720$ pixels. Ambient music was playing in the background (The Guild of Ambience, 2017). See for an impression the supplementary video (Video 1).

\subsection{Participants and Data Collection}

Seventy participants (58 females, 11 males, 1 preferred not to answer; $M_{\text {age }}=22.7$ years) were recruited from Radboud University SONA system. After their arrival to the lab in the Behavioural Science Institute, they read the information page and gave their informed consent. Following their approval, they were randomly assigned to two groups (interactive: 31 females, four males; $M_{\text {age }}=22.7$ years/non-interactive: 27 females, seven males, one participant indicated 'do not prefer to answer'; $M_{\text {age }}=22.8$ years) and taken to the room with the artwork. The participants that were assigned to the interactive condition encountered the artwork as mentioned above. However, the participants in the non-interactive condition encountered a non-interactive version of the artwork. This was achieved by changing the code of the artwork to have virtual agents that walked around in order to create similar visual input to that of interactive participants. The main difference between the interactive artwork is that this version of the artwork is unresponsive to the movements of the participants. Thus, for them, the artwork was a piece of video art. Participants who completed the study were rewarded either student credits or $€ 5$ for their 20-minute-long participation.

\subsection{Procedure}

Participants were assigned to either the interactive or the non-interactive condition once they signed the informed consent. After they were assigned to their conditions, the participants were taken to the artwork and were informed as follows: "You are going to enter the room where the artwork is (Fig. 2). I am not going to enter with you. There are two lines on the floor; stay between the lines and explore the artwork. There is no beginning or end, so when you feel like you have explored enough, you can come out." The title or the description of the artwork was not disclosed to the participants. The time, starting from 


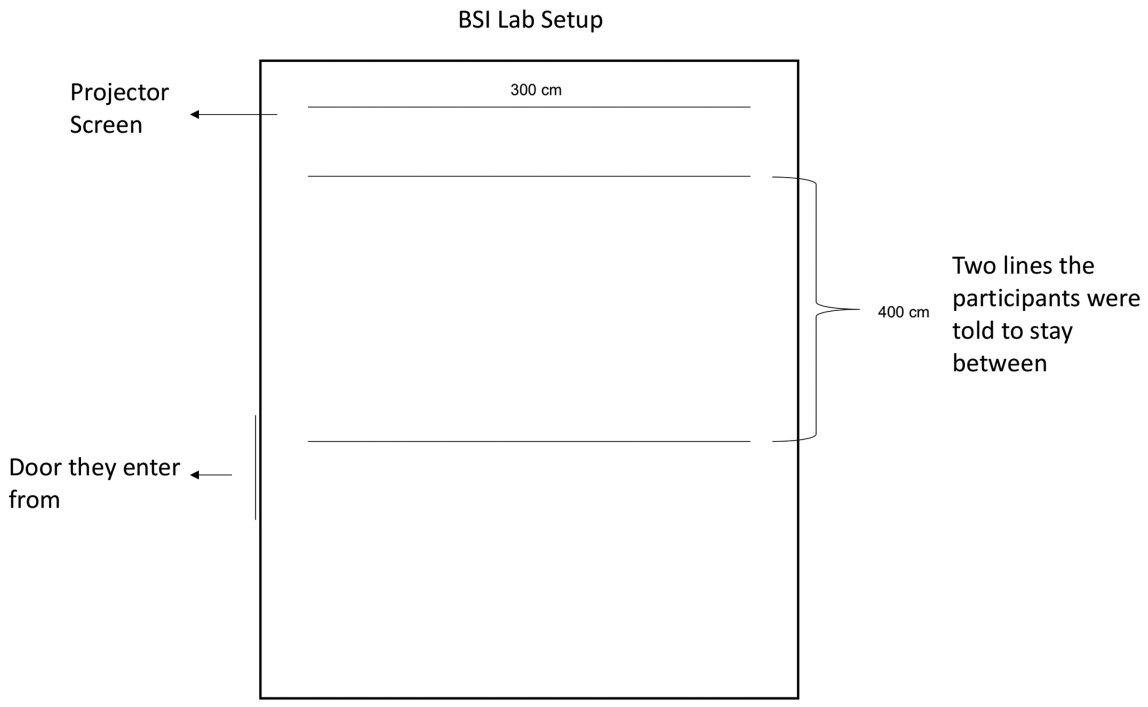

Figure 2. The lab setup

entering the room until exiting the room, was recorded. After they exited the room, they were taken to a cubicle with a computer to fill out a questionnaire.

The questionnaire included two main parts; the Aesthemos questionnaire (Schindler et al., 2017) to test the emotional reactions and the Unusual Uses Task (Guildford, 1967) to test creative thinking, specifically cognitive flexibility. In addition to these main parts, further exploratory measurements were taken, described in the section 2.4. Measurements below, on participants' experience of the artwork.

\subsection{Measurements}

\subsubsection{Prototypical Aesthetic Emotions}

This includes the emotions being moved, surprise, fascination, feeling of beauty, and awe that were tested with two questions each in the prototypical aesthetic emotions factor of the Aesthemos questionnaire (Schindler et al., 2017). The rest of the questionnaire was used for exploratory purposes. Aesthemos (Schindler et al., 2017) tests aesthetic emotions with seven factors (negative emotions, prototypical aesthetic emotions, epistemic emotions, animation, nostalgia, sadness, amusement) with 21 subscales in a five-point Likert scale (1: "Not at all"-5: "Very"). Cronbach's alpha for the seven factors were as follows; prototypical aesthetic emotions factor, 0.87 ; negative emotions factor, 0.82; amusement factor, 0.79; epistemic emotions factor, 0.83; animation factor, 0.86 ; nostalgia factor, 0.74 ; sadness factor, 0.45 . Additionally, the 
Cronbach's alpha for the subscales of PAE were as follows; fascination, 0.85; beauty, 0.83; being moved, 0.78; awe, 0.68; and surprise, 0.53 .

\subsubsection{Cognitive Flexibility}

This was measured with the Unusual Uses Task by Guildford (1967). The task required participants to generate and list as many ideas as they can in response to the question 'What can you do with a paperclip?' in two minutes. The cognitive flexibility score was achieved by coding each idea into a category (by two independent raters; inter-rater reliability was 0.88 ). The total number of categories of each participant was their cognitive flexibility score.

\subsubsection{Art Experience Questionnaire}

This was used to assess previous art knowledge of the participants, such as how many art classes they had taken (Chatterjee et al., 2010). Chatterjee and colleagues (2010) consider those who score higher than 13 to be higher in art expertise. However, we used art expertise as a continuous variable rather than using this cutoff number as this cutoff was arbitrary (see also Specker et al., 2020). Our descriptive analyses showed that art expertise was highly positively skewed in our sample, meaning that the majority of the participants did not have high expertise in art. Therefore, we decided not to draw any conclusions from our sample about how art expertise affects general evaluation of interactive art.

\subsubsection{General Evaluation of the Artwork}

"What is your general evaluation of the artwork?" was asked on a 10-point Likert scale (1: "Displeasing"-10: "Pleasing"). This was used as an indication of participants' enjoyment of the artwork (Silvia et al., 2005).

\subsubsection{Extra Questions}

These included questions that we considered to have an effect on the experience but were not in the questionnaires. These questions were about how much involvement, interestingness, unexpectedness, control participants felt. These were asked in a 5-point Likert scale (1: "Not at all"-5: "Very").

\subsubsection{Interactivity Check}

To check if participants realized that the artwork was interactive and that they could control the artwork by changing their position in the assigned area, participants in the interactive condition were asked "Do you think the artwork was responding to your movements? If so, when did you realise the interaction?" They were given four choices: immediately, in the first minute, around the end, never. Out of the 35 people in the interactive condition, 22.8\% responded that they realized the interaction immediately, 54.2\% realized it in 
the first minute, $17.1 \%$ realized it around the end, and 5.7\% never realized it. For this study, the two participants that never realized there was an interaction were not excluded from the analyses as it was not an exclusion criterion in the preregistration. However, no significant change was found when they were exploratorily removed. This question was not included in the questionnaire that the participants in the non-interactive condition completed to avoid any confusion that might arise from it.

\subsubsection{Meaning of the Artwork}

The open-ended question "What do you think the artwork meant?" was asked to gather further insight into the experience of the artworks (Appendix A).

\subsubsection{Movement}

The open-ended question "How did you explore the artwork? Did you move in certain ways, walked in certain ways?" was asked to gather information about how the participants moved in the room (Appendix B). The answers were coded into two categories: no movement/movement (walking side to side and/ or closer and further away).

\subsubsection{Demographics}

As the last section of the questionnaire, participants filled in their age and their sex (options; female, male, prefer not to answer).

\subsubsection{Time Spent Viewing the Artwork}

This was recorded by the experimenter from the moment the participants entered the room where the artwork was exhibited until they exited the room.

\section{Results}

The data were analysed in R Studio version 1.1.463 (R Studio Team, 2018) and the confirmatory analyses were pre-registered (\#35308; AsPredicted, 2020).

For the first hypothesis, we tested whether those who encountered an interactive artwork had higher PAE than those who encountered a non-interactive artwork. This was tested with a multivariate analysis of variance (MANOVA), comparing the five subscales of emotions included in the PAE factor in the interactive condition with those in the non-interactive condition. The multivariate result was not significant, Pillai's trace $=0.12, F_{1,65}=1.76, p=0.13$ (Fig. 3). Thus, we failed to confirm our hypothesis. However, the univariate $F$ tests with Bonferroni adjustment following the MANOVA showed that participants differed significantly in the beauty subscale ( $p=0.043$, Fig. 3$)$, and the interactive group scored higher than the non-interactive. The two conditions did not differ in the subscales fascination, awe, moved, and surprise $(p s>0.21)$. 


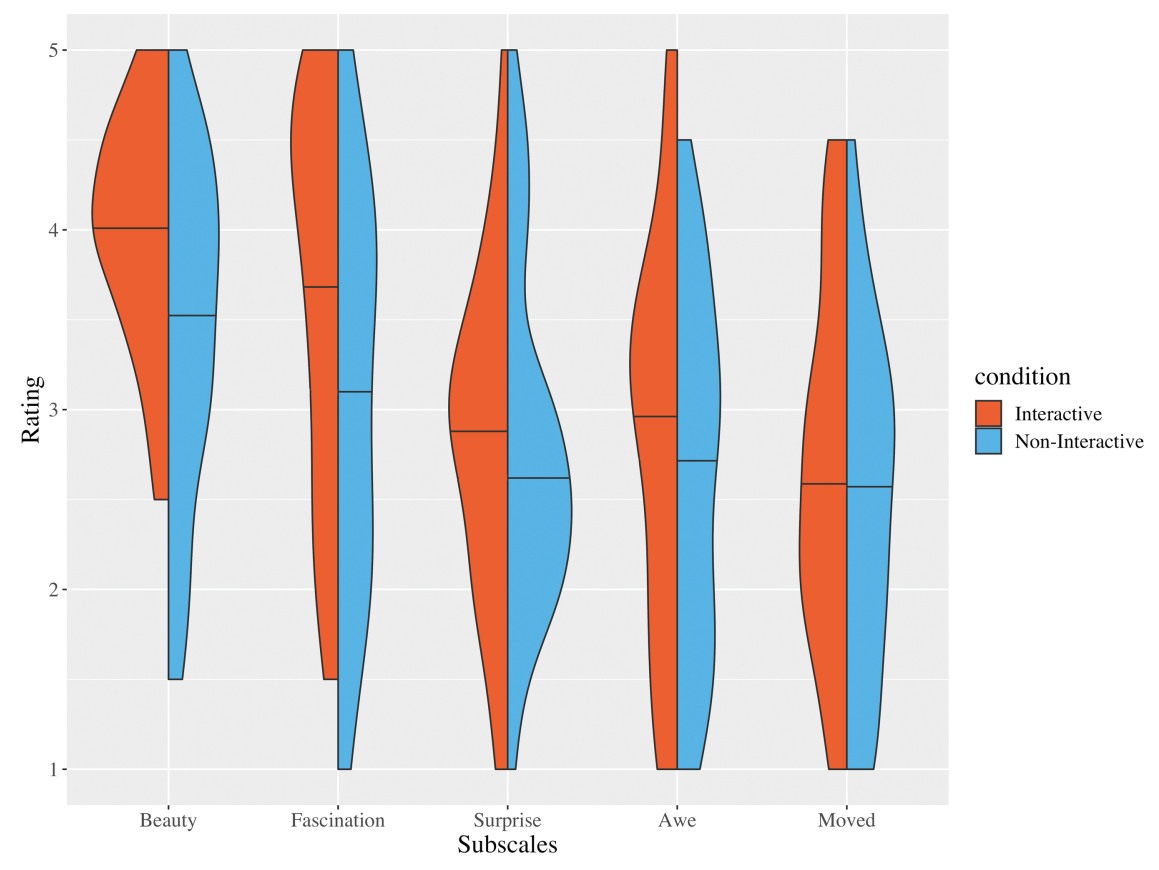

Figure 3. Intensity of prototypical aesthetic emotion subscales between the two conditions. Difference in subscales of PAE; beauty, fascination, surprise, awe, and being moved shown with half violin plots. The colours differentiate between different conditions. The lines in the middle indicate the median of the conditions. Beauty and fascination subscales were significantly higher in the interactive condition than in the non-interactive condition.

The second hypothesis was investigated with an independent $t$-test comparing the mean cognitive flexibility score between the interactive and the noninteractive condition. Our hypothesis was not confirmed: There was no difference in cognitive flexibility between participants in the interactive and participants in the non-interactive condition, $t_{64.142}=0.90, p=0.37$, Cohen's $d=0.27$ $\left(M_{\text {interactive }}=5.02, \mathrm{SD}_{\text {interactive }}=2.06 ; M_{\text {non-interactive }}=4.62, \mathrm{SD}_{\text {non-interactive }}=1.61\right)$. This is in line with the $t$-tests investigating surprise, $t_{67.911}=0.19, p=1$ $\left(M_{\text {interactive }}=2.82, \mathrm{SD}_{\text {interactive }}=0.92 ; M_{\text {non-interactive }}=2.78, \mathrm{SD}_{\text {non-interactive }}=0.95\right)$ and unexpectedness, $t_{67.706}=-0.85, p=0.39\left(M_{\text {interactive }}=4.11, \mathrm{SD}_{\text {interactive }}=0.99\right.$; $\left.M_{\text {non-interactive }}=3.88, \mathrm{SD}_{\text {non-interactive }}=1.15\right)$ that showed non-significant differences between interactive and non-interactive as surprise and unexpectedness could be indicators of schema violations.

\subsection{Exploratory Analyses}

To further investigate the effects of interactivity, we asked extra questions on how much control and involvement people thought they had over the 
artwork, as well as how interesting and unexpected they found the artwork. The answers were investigated with independent $t$-tests, comparing the means of the abovementioned concepts between the two conditions. Participants in the interactive condition reported higher control than those in the non-interactive condition, $t_{67.91}=7.79, p<0.001\left(M_{\text {interactive }}=3.80, \mathrm{SD}_{\text {interactive }}=1.02\right.$; $\left.M_{\text {non-interactive }}=1.85, \mathrm{SD}_{\text {non-interactive }}=1.06\right)$. This is in line with the control participants actually had on the artwork. It should be noted that some participants in the non-interactive condition did not report " 1 - Not at all", meaning that they might have attributed some control over the artwork. There was no difference between groups in how involved they felt, $p=0.14$, how unexpected, $p=0.37$, or how interesting they found the artwork, $p=0.07$.

The remaining six factors of the Aesthemos scale (Schindler et al., 2017) were investigated with independent $t$-tests comparing the means of different factors between the interactive and non-interactive conditions. Participants in the non-interactive condition scored significantly higher on the negative emotions factor (which includes uneasiness, ugliness, boredom, confusion, and anger subscales) than the participants in the interactive condition, $t_{66.48}=-2.42$,

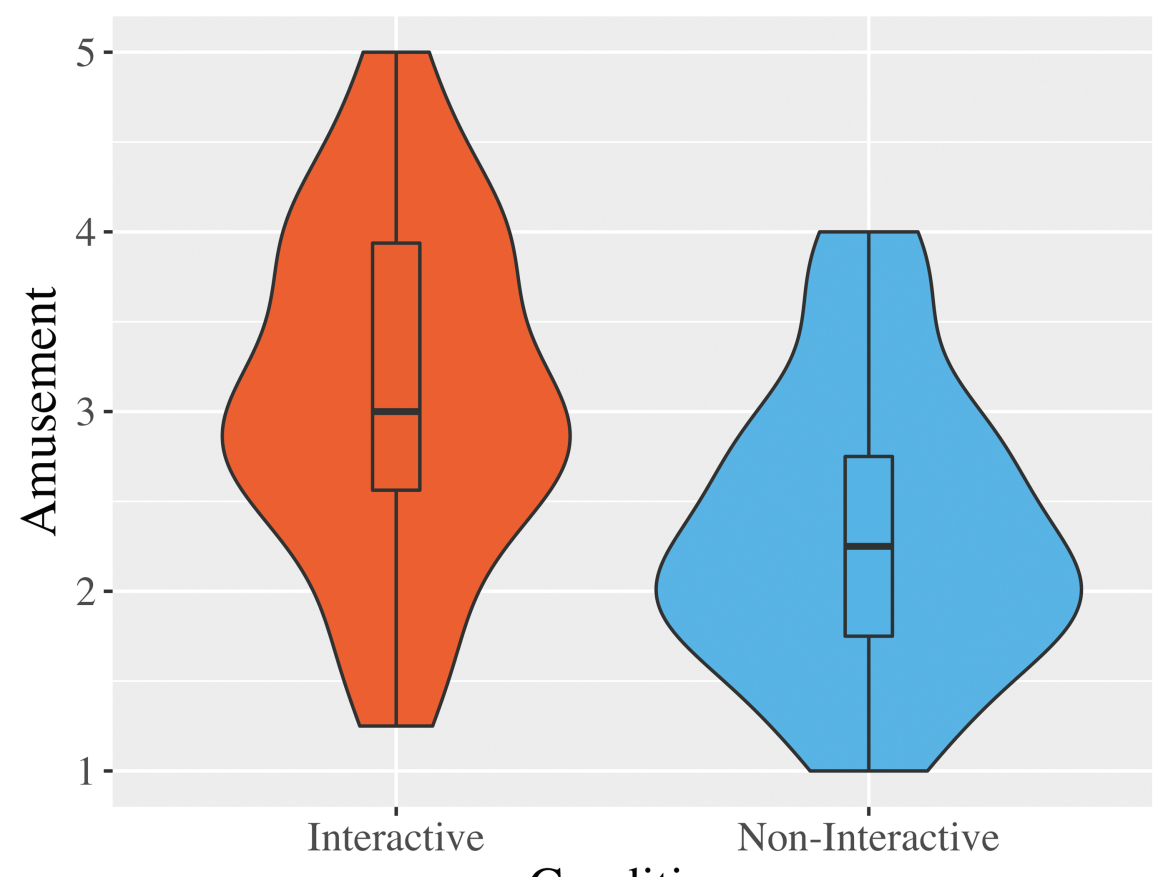

Condition

Figure 4. Intensity of negative emotions and amusement between conditions. Significant difference in negative emotions and amusement factors in the Aesthemos scale (Schindler et al., 2017) between interactive and non-interactive conditions. 


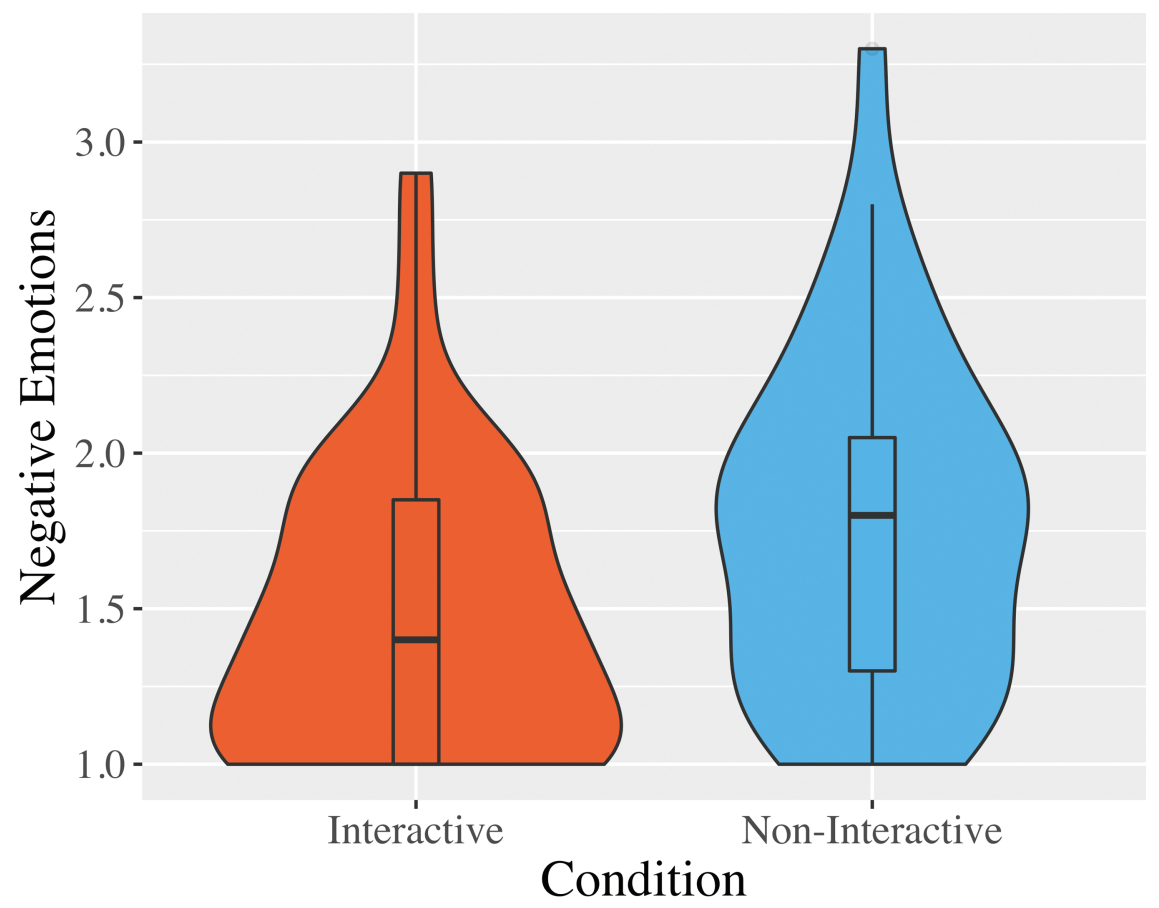

Figure 4. Cont.

$p=0.018$, Cohen's $d=0.58\left(M_{\text {interactive }}=1.47, \mathrm{SD}_{\text {interactive }}=0.92 ; M_{\text {non- }}\right.$ interactive $=1.76, \mathrm{SD}_{\text {non-interactive }}=0.78 ;$ Fig. 4$)$. This shows that participants in the non-interactive condition experienced negative emotions more intensely than those in the interactive condition. And in contrast, participants in the interactive condition performed significantly higher in the amusement factor (which includes humour and joy subscales) than people in the non-interactive condition, $t_{64.68}=3.74, p<0.001$, Cohen's $d=0.90\left(M_{\text {interactive }}=3.11\right.$, $\mathrm{SD}_{\text {interactive }}=0.47 ; M_{\text {non-interactive }}=2.33, \mathrm{SD}_{\text {non-interactive }}=0.55 ;$ Fig. 4$)$, indicating that people had more fun in the interactive condition. Participants did not differ in the other four factors of the scale (epistemic emotions, animation, nostalgia/relaxation, sadness, $p s>0.12$ ).

The general evaluation of the artwork was negatively skewed for both conditions, thus before conducting an analysis, we log-transformed the variable. When the general evaluation of the artwork was investigated with an independent $t$-test, we found a significant difference between groups, indicating higher enjoyment of art in the interactive condition, $t_{67.95}=2.79, p=0.006$ $\left(M_{\text {interactive }}=7.71, \quad \mathrm{SD}_{\text {interactive }}=1.48 ; M_{\text {non-interactive }}=6.54, \mathrm{SD}_{\text {non- }}\right.$ interactive $=2.07)$. To gain insight into whether PAE might have influenced the general evaluation of the artwork, we conducted a linear regression with PAE 
and interactivity as predictors for general evaluation, Adjusted $R^{2}=0.49$, $F_{3,63}=22.77, p<0.001$. Our analysis indicated that there was a main effect of PAE, $t_{63}=3.25, p<0.001$, and interactivity $t_{63}=-2.51, p=0.014$. There was also a significant interaction between PAE and interactivity, $t_{63}=0.22$, $p=0.037$ (Fig. 5). The interaction suggests that for the participants in the noninteractive condition having higher PAE was crucial to have higher evaluation whereas that was not the case for the participants in the interactive condition. Participants in the interactive condition were less dependent on having higher PAE to indicate higher evaluation. Thus, interactivity might have been effective enough to imply higher evaluation of the artwork in the interactive condition, regardless of aesthetic experience.

The average time spent in the room with the artwork was four minutes for both interactive and non-interactive conditions, thus did not differ significantly between groups $t_{57.104}=-0.12, p=0.90\left(M_{\text {interactive }}=4.05, \mathrm{SD}_{\text {interactive }}=2.33\right.$; $\left.M_{\text {non-interactive }}=4.10, \mathrm{SD}_{\text {non-interactive }}=1.45\right)$.

To have a visual outlook on the emotional experience of participants in both conditions, we conducted partial correlational network analyses for both conditions (Epskamp et al., 2012; Fig. 6) inspired by Pelowski and colleagues' (2018) study on installation art. These analyses aimed to provide the partial correlations between the 21 subscales of emotions in the Aesthemos scale (Schindler et al., 2017) that participants have reported on their experience they had with the artwork. Partial correlational networks are commonly used to estimate psychological networks with continuous data (Epskamp and Fried,

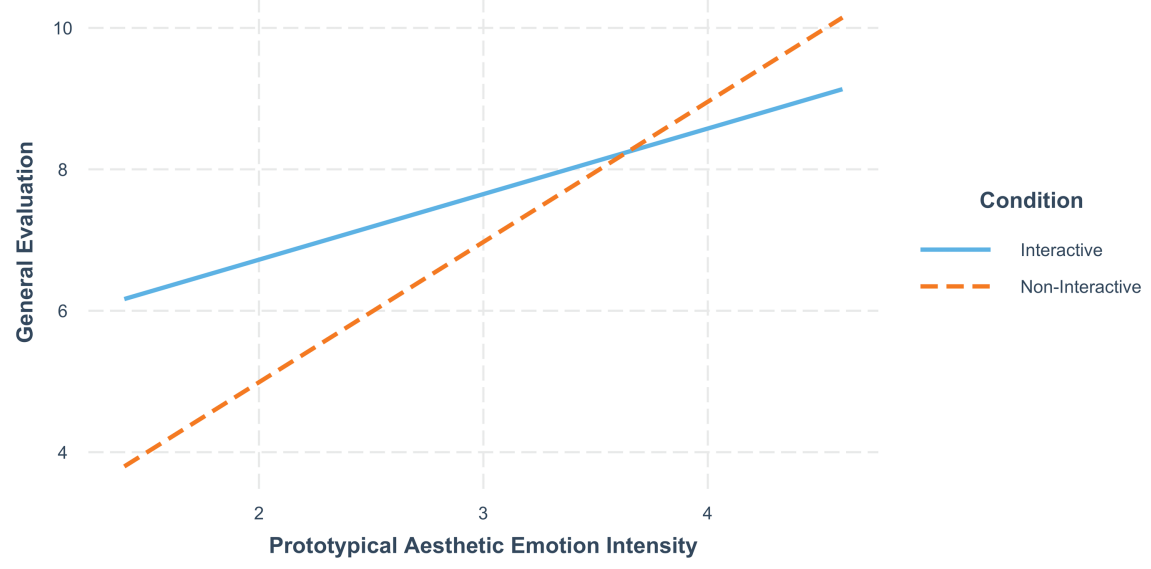

Figure 5. Intensity of prototypical aesthetic emotions and condition predicting general evaluation. Linear regression showing PAE and condition predicting the general evaluation of the artwork for both conditions. There was a significant interaction effect of PAE and condition on general evaluation. 

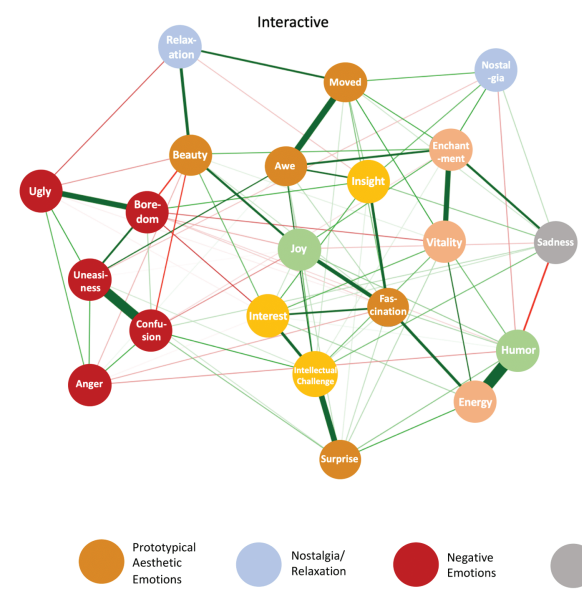
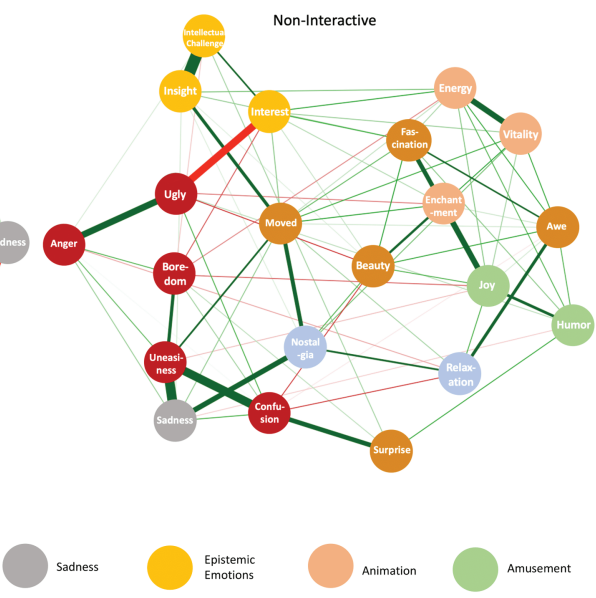

Figure 6. Network model of emotions. Network model of reported emotions in the two conditions of interactive art. Analyses were conducted using the R package qgraph, graphical LASSO regularization (Epskamp et al., 2012). Individual emotions are shown as circles; green lines indicate positive partial correlations that have survived the regularization procedure; red lines indicate negative partial correlations. Line thickness indicates strength of correlations. Relative distance between items suggests strength of the connection as a function of the entire network. Colours are added for a better distinction of the seven factors of the Aesthemos scale (Schindler et al., 2017).

2018). The networks consist of partial correlation coefficients between nodes visualised in a weighted network structure. LASSO regularisation is commonly used to limit spurious edges in these analyses (Epskamp and Fried, 2018). Different tuning parameters can be set for this regularisation. For confirmatory analyses, setting the parameter to 0.5 is advised, and for exploratory analyses, setting the parameter lower is accepted. In our analyses, a tuning hyperparameter higher than 0.1 gave us an empty model, possibly due to our relatively small sample size, and thus, we set the parameter to 0.1 . Even though it is not uncommon to use lower parameters for exploratory purposes, we have noted that lowering the hyperparameter increases the likelihood that the network might contain spurious edges. Edges that are mentioned are the lines between the nodes as seen in Fig. 6. These edges differ in colour and weight, which indicate the magnitude and the direction of the relationship between two nodes. Green lines indicate positive and red lines negative partial correlations. The thicker and more saturated the line is, the stronger the relationship between two nodes that the line connects (Epskamp and Fried, 2017). In addition to these visualisations, centrality indices of the network as seen in Fig. 7 can show how important nodes are in the network using three main indices, which are "Node strength, which takes the sum of absolute edge weights connected to each node, closeness, which takes the inverse of the sum of distances 
from one node to all other nodes in the network, and betweenness, which quantifies how often one node is in the shortest paths between other nodes" (Epskamp and Fried, 2018, p. 10). We have ordered the network models by their node strength (Fig. 7) to make the interpretation easier.

The network model for the interactive condition shows the prevalence of intellectual challenge, and some PAE. The strongest nodes are intellectual challenge and fascination, followed by enchantment, beauty and being moved. Intellectual challenge being the strongest node might imply that exploring and finding out what is happening was challenging for the participants; however, this challenge correlates positively with interest and other positive emotions. This might mean that challenge was regarded as a rewarding experience. The visual shows that fascination, for example, was positively correlated with other positive emotions. On the other side, negative emotions such as uneasiness, confusion, ugliness and boredom cluster together and positively correlate with each other, meaning that once you experience one of those emotions, you are also likely to experience the others as well. However, all these emotions are less

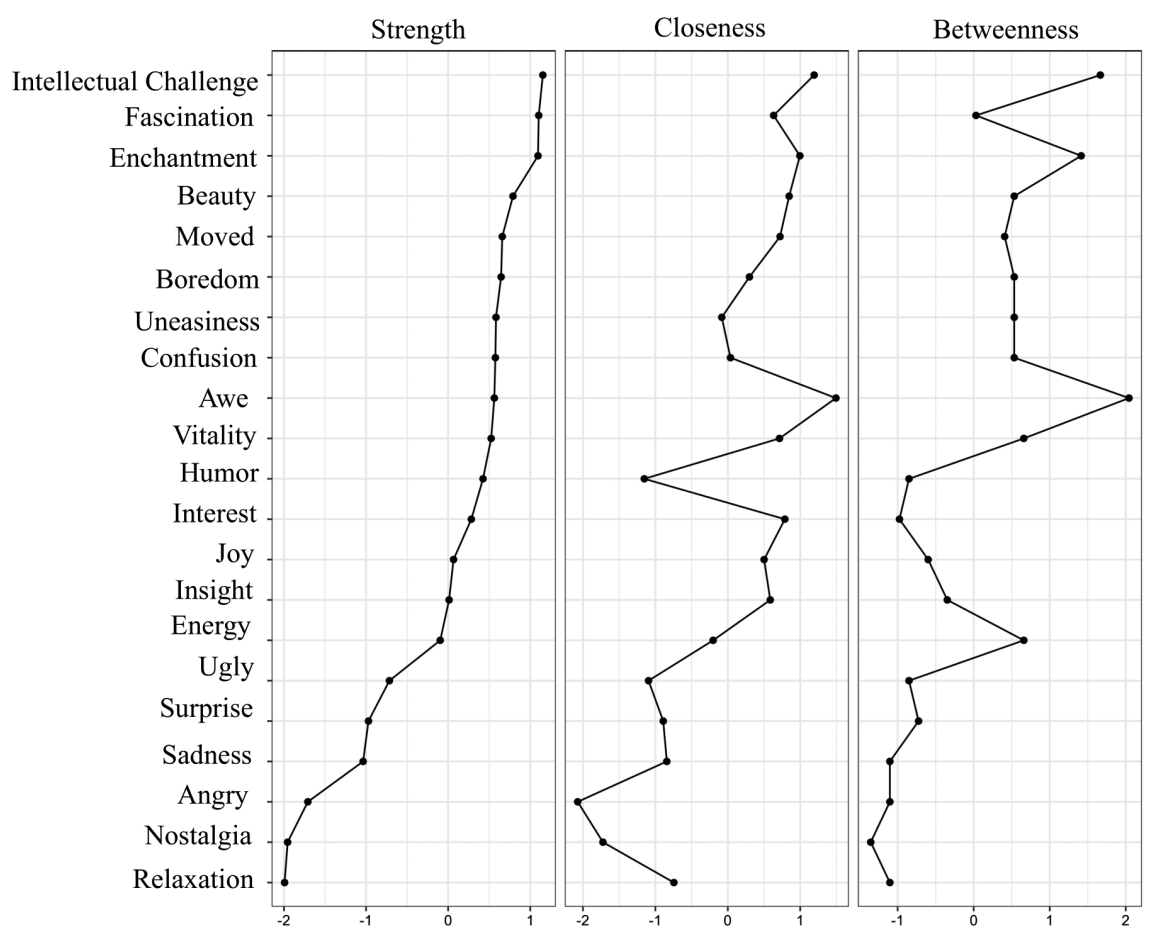

Figure 7. Network model indices: (1) interactive condition; (2) non-interactive condition. Strength, Closeness and Betweenness scores between emotion terms in the network models. The scores are ordered according to their Strength. $Z$-scores are shown on the $X$-axis rather than raw centrality indices. 


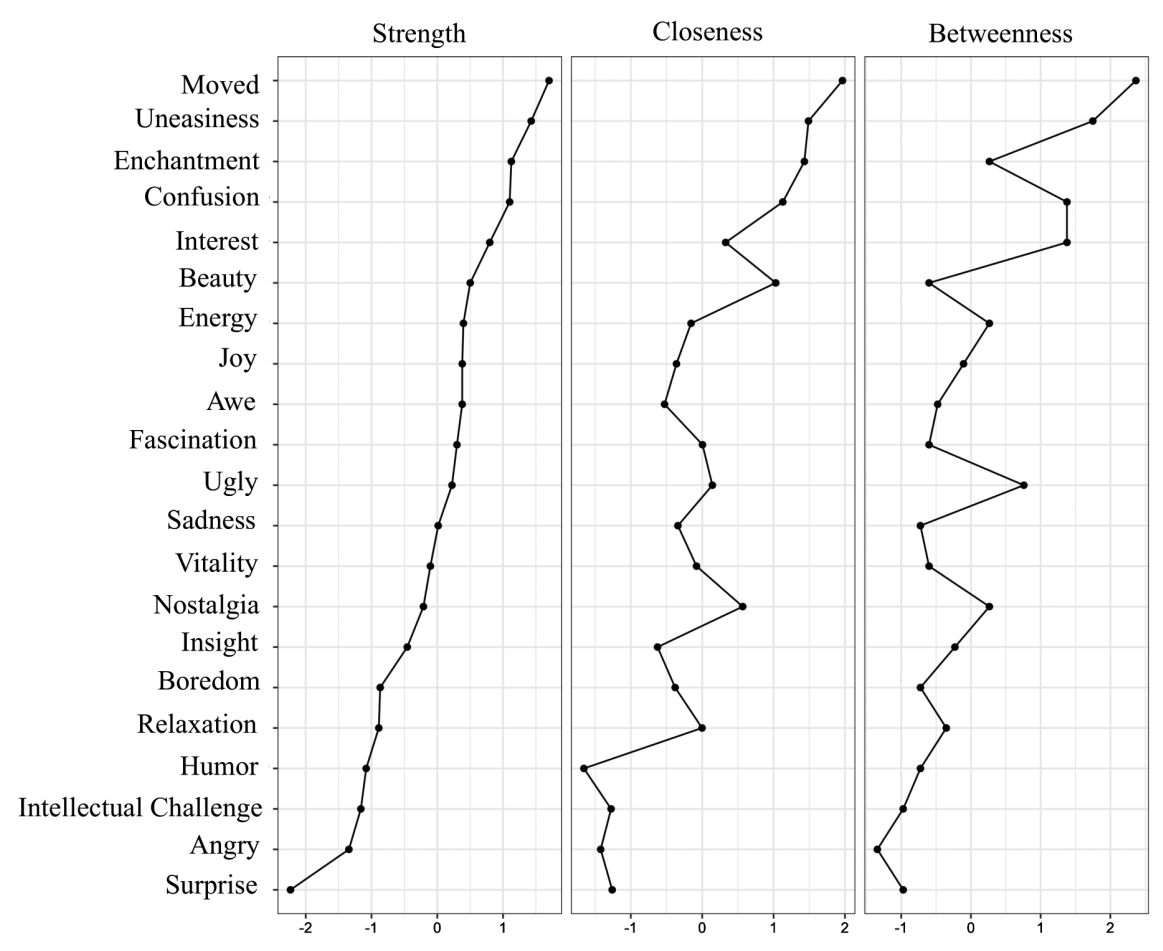

Figure 7. Cont.

strong, meaning that they are not as influential in the total experience. We see that negative emotions correlate only very little with the positive emotions. One of the interesting things is that sadness and nostalgia are positively correlated with several positive emotions, for example insight and enchantment. This might be a way that people appraise negative emotions to more positive outcomes while interacting with an artwork. The network model for the noninteractive condition shows a prevalence of a mixture of PAE, such as being moved, with several negative emotions, such as uneasiness and confusion. The analysis indicates that the link between these negative and positive emotions are stronger in this model, with thicker green lines connecting these emotions with each other. For example, uneasiness, nostalgia and sadness lead to being moved and confusion leads to surprise. These results are in line with the independent $t$-test result showing the prevalence of negative emotions in this condition compared to the interactive condition. However, these negative emotions do lead to being moved in the end, possibly due to the appraisal of negative emotions to more positive emotions while interacting with an artwork. Thus, this is in line with the subscale being moved not being significantly different between groups, as this condition also was moving for the participants. 
The open-ended question of what the artwork meant revealed a pattern similar to the aforementioned results (see Appendix A for the answers of participants). Being dynamic, perception of humans, visual illusions, and the ways of seeing things were mentioned while explaining the interactive artwork. Additionally, the interactivity was being mentioned more frequently than the photographs inside the artwork. Participants in the non-interactive condition reported being trapped, being caged, and being depressed, which is in line with the higher negative emotions they experienced. As there was no interactivity in this condition, participants were mentioning the content of the photographs. This might indicate that interactivity is taking over the meaning of the artwork and restructuring the content of the artwork.

At last, regarding the open-ended question "How did you explore the artwork? Did you move in certain ways, walk in certain ways?", in the interactive condition two participants reported standing still, 33 participants reported moving, either walking side to side and/or closer and further away. In the noninteractive condition 17 participants reported standing still, and 18 reported to move. Thus, the participants that view an interactive artwork are more likely to move than those who view the non-interactive counterpart, $\chi_{1,70}^{2}=16.254$, $p<0.001$. This could be one of the underlying factors that might explain how the interactivity of an artwork could have an effect on the spectators.

\section{Discussion}

This study was designed to investigate how interactivity affects aesthetic experience and creativity in a controlled environment. Even though we have not confirmed either of our hypotheses, our results suggested that the participants in the interactive condition found the artwork more beautiful regardless of the similarity of the visual input with the non-interactive condition. Thus, the difference in beauty can be explained by the interactivity of the artwork. Moreover, emotions have been regarded as a strong predictor for art enjoyment (Gerger et al., 2018). The interaction between PAE and interactivity indicates that interactivity might change the relationship between emotion and enjoyment. The results suggest that participants in the interactive condition were less dependent on having higher PAE to feel more enjoyment of the artwork, thus showing that interactivity might be taking over the role of PAE and enhance enjoyment by a different route. Additionally, when we investigated the network models to understand the emotion pathways, we saw that participants in both conditions were moved by the artwork. However, the emotions that led to being moved were different. In the interactive condition, people were moved through more positive emotions such as beauty, fascination, and to a lesser extent, vitality, and interest. However, in the non-interactive condition, people were moved and enchanted through more negative emotions such 
as uneasiness and confusion. This is in line with people in the non-interactive condition experiencing higher negative emotion intensity, which supports the argument that the art context affects emotion appraisal processes, allowing negative stimuli to be judged aesthetically more positively (Gerger et al., 2014). Thus, the negative emotions the participants in the non-interactive condition experienced were interpreted as being moved by the artwork.

There could be several explanations for why we did not find any difference in cognitive flexibility between conditions. First, it could be the case that all of the participants experienced schema violations. A reason for this might be that the experiment was already something new for the participants even in the non-interactive condition, such that all the participants might have experienced schema violations to some degree. We do not know if there was a change in creativity in either condition as we did not have a pre-test score of creativity; however, the decision to not have a baseline was made in order to avoid priming participants before they experienced the artwork. Secondly, it could be the case that none of the participants experienced schema violations. This could be explained either by interactivity not being a factor that influences cognitive flexibility, or by the rather subtle nature of the interaction that our artwork was providing. It might not be unusual or unexpected enough to trigger schema violations, or as Pelowski and colleagues suggest (2017), the disruption might be minor due to the low self-interest participants have invested in the artworks. This would be in line with their findings suggesting higher bemusement and pleasure related to the minor disruption and with our findings that show higher amusement and enjoyment in the interactive condition. Next to that, there is also research that shows that schema violations increase or impede cognitive flexibility depending on the participants' need for structure (Goclowska et al., 2014). As we have not tested the participants' need for structure, we cannot say whether this might have been a confound or not. In future research, certain personal characteristics like this could be taken into consideration. A final reason for the null effect could be due to the scoring of the Unusual Uses Task (Guildford, 1967). While the scoring in this study was done by two independent coders by counting the different categories, Silvia and colleagues (2008) argue that there can be better ways to score cognitive flexibility score than counting different categories. They suggest asking the participants to score their best two ideas and evaluate those two ideas at the end. Another possible way to infer whether participants had their schemas violated is by looking at how surprised they were. The non-significance in surprise also is in line with our findings of cognitive flexibility. Thus, while interactive art involves the spectator in the creative process, we did not capture an effect of this involvement on cognitive flexibility scores of our participants. Whether this creative involvement indeed has an effect on the spectators can be examined in further studies with different methodology. 
It should be noted that this lab study was different from usual lab studies conducted on art perception. Instead of showing the artwork on a computer screen in the laboratory, which is what a usual lab study consists of, participants saw a full-sized artwork. Additionally, unlike the time limit each artwork usually gets in lab studies, in this study participants had as much time as they wanted to spend with the artwork. This resulted in an interesting outcome. Time spent with the artwork was quite different than what was reported in previous studies (Carbon, 2017). Carbon (2017) states that in laboratory studies people are shown artworks for around $6 \mathrm{~s}$, and in museums people spent on average $50 \mathrm{~s}$ per artwork. In our study, the time spent is approximately four times that number for both of the conditions. In that sense, this study might be closer to a museum study than to a lab study. Both conditions having the same time average is intriguing and could be explained by different reasons underlying these conditions. For both conditions, the time spent with the artwork could be a consequence of having no other artwork in the room, or it could be due to the fact that it is a gradually changing artwork and discovering all of the possible photographs could take around that time either by interacting with them yourself in the interactive condition, or the video showing all the possibilities in the non-interactive condition. Thus, there is more to discover within the time frame that they observe the artwork for both of the conditions than what Carbon (2017) states. Nevertheless, longer time duration is argued to be associated with more profound experiences of art (Leder and Nadal, 2014). However, even though in both conditions a similar time period was spent with the artwork, the participants in the interactive condition had significantly higher evaluations of the artwork than the ones in the non-interactive condition. This suggests that the difference in evaluation could be explained by the interactivity of the artwork in the first condition. Further investigation is needed to see whether these factors, such as time spent viewing, that affect aesthetic experience differ between different types of art.

This study had several limitations that might affect its generalisability. Even though we have reached our pre-registered sample size (based on other studies in the field, e.g., Szubielska et al., 2019), replications with larger sample sizes, also under different circumstances, are recommended. Additionally, the environment in which this study took place was not optimal, as a laboratory is obviously not an ecologically valid environment for aesthetic experiences. As mentioned before, the context in which the art is perceived affects the aesthetic experience greatly for most art types (Carbon, 2017; Specker et al., 2017; Szubielska, 2019). Thus, even though we have found effects of interactivity in the laboratory context, one should be careful to generalise this to a museum context in which there are several different factors that play a role in the aesthetic experience (e.g., the social aspect of museums). Thus, further studies should investigate interactive art in a museum context (see Note 1). 
Another important limitation of the current study is that we used only one work of art. This means that we should be careful when drawing conclusions about the effect of interactive artworks in general. Looking back, we could identify two aspects of the artwork that influence its generalizability. First, the artwork had a bit of a negative undertone, by having predominantly blue and red colours. Indeed, participants in the non-interactive condition mentioned more negative emotions in their answers. It would be interesting to examine whether people find interactive art more positive in general, or whether that has to do with this specific artwork. Second, the interactivity of the artwork that we used in our study was quite subtle. This might have led some people to not realise that the artwork was interactive, causing them to not move or explore, and thus being excluded from our analyses. Other participants might have noted only one part of the interaction, for example, realising only the interaction effects of the movements in parallel to the screen (which was more evident), but not the effect due to movements perpendicular to the screen. Such different levels of understanding might have an influence on the experience of the artwork. Thus, the degree of (realised) interactivity could be investigated as a factor in future studies. In addition to subtlety, different types of interactivity can be used in future studies. In the current study we used a visual interactive artwork for several reasons; first, because vision is often argued to be our most trusted sense (Spence et al., 2012), and second, we did not want to have other senses as a confounding variable. However, there could be different types of interactivity tapping into different senses, auditory, somatosensory, olfactory, and even gustatory. These senses are differentiated in aesthetics as they lead to hedonic value from their own paths (Skov and Nadal, 2020), and thus having interactive control over such non-visual sensory input might have different effects on the spectator. Future studies could investigate whether the different types would have a differential effect, or whether using multiple senses at the same time would enhance the experience even more.

In this study, we relied on retrospective self-report measures of emotional experience. Even though this is the easiest way, it has certain limitations. For example, by using self-report, we expected participants to express their emotions with words, making a leap from experience to language, which might produce problems in the expression of the experience (Robinson and Altarriba, 2014). More so, the native language of most of our participants was not English. Even though our inclusion criterion was good understanding of English, emotion words might have different implications in one's native language than in their second language. An example of this problem arising in our study can be seen in the low reliability of the surprise subscale which consists of the items "Surprised me" and "Baffled me". While the first item is indicating surprise in a clearer way, the second item "Baffled me" might have been more confusing or have negative connotations for the participants. A way 
to tackle this problem is to incorporate self-report measures with physiological measures, such as heart rate variability (Tschacher et al., 2012). Tschacher and colleagues (2012) have shown that physiological symptoms were significantly associated to the self-reported emotional experience in representational art. Thus, it is promising to add physiological measures to more reliably investigate interactive art experience in future studies. However, it should be taken account that this might not be ideal with interactive art that requires movement as the movement can have an effect on the heart rate variability.

In conclusion, we investigated how interactivity affects aesthetic experience and creativity in an experimental setting. The results suggest that interactivity might be a factor that plays a role in shaping the prevalence of specific emotions (such as beauty). Exploratory analyses indicate that interactivity redirects the attention away from the content of the artwork towards the interaction itself. Additionally, the current results revealed no indication that interactivity has an effect on creativity. By exploring interactivity for the first time, we have seen promising results that future studies should develop and continue to investigate. With art becoming our solace in gloomy days, it is more than crucial to investigate factors that play a role in our experience with it.

\section{Note}

1. We actually planned and partially conducted a follow-up study in a gallery in Nijmegen to account for ecological validity. However, the data collection process was disturbed by the events caused by COVID-19.

\section{References}

An, D. and Youn, N. (2017). The inspirational power of arts on creativity, J. Bus. Res. 85, 467-475. doi: 10.1016/j.jbusres.2017.10.025.

AsPredicted (2020). Home. Retrieved from https://aspredicted.org/.

Berlyne, D. E. (1970). Novelty, complexity and hedonic value, Percept. Psychophys. 8, 279286. doi: 10.3758/BF03212593.

Brinck, I. (2018). Empathy, engagement, entrainment: the interaction dynamics of aesthetic experience, Cogn. Proc. 19, 201-213. doi: 10.1007/s10339-017-0805-x.

Carbon, C.-C. (2017). Art perception in the museum: How we spend time and space in art exhibitions, I-perception 8, 2041669517694184 . doi: 10.1177/2041669517694184.

Carbon., C.-C. (2019). Empirical approaches to studying art experience, J. Percept. Imaging, 2, 010501-1-010501-7. doi: 10.2352/J.Percept.Imaging.2019.2.1.010501.

Chatterjee, A., Widick, P., Sternschein, R., Smith, W. B. II and Bromberger, B. (2010). The assessment of art attributes, Empir. Stud. Arts 28, 207-222. doi: 10.2190/EM.28.2.f.

Cuypers, K., Krokstad, S., Lingaas Holmen, T., Knudtsen, M.S., Bygren, L.O. and Holmen, J. (2012). Patterns of receptive and creative cultural activities and their association with 
perceived health, anxiety, depression and satisfaction with life among adults: the HUNT study, Norway, J. Epidemiol. Commun Health 66, 698-703. doi: 10.1136/jech.2010.113571.

Dewey, J. (1958). Experience and Nature. Dover Publications, New York, NY, USA.

Epskamp, S. and Fried, E. I. (2018). A tutorial on regularized partial correlation networks, Psychol. Methods 23, 617-634. doi: 10.1037/met0000167.

Epskamp, S., Cramer, A. O. J., Waldorp, L. J., Schmittmann, V. D. and Borsboom, D. (2012). qgraph: Network visualizations of relationships in psychometric data, J. Stat. Softw. 48, 1-18. doi: 10.18637/jss.v048.i04.

Gerger, G., Leder, H. and Kremer, A. (2014). Context effects on emotional and aesthetic evaluations of artworks and IAPS pictures, Acta Psychol. 151, 174-183. doi: 10.1016/j. actpsy.2014.06.008.

Gerger, G., Pelowski, M. and Leder, H. (2018). Empathy, Einfühlung, and aesthetic experience: the effect of emotion contagion on appreciation of representational and abstract art using fEMG and SCR, Cogn. Proc. 19, 147-165. doi: 10.1007/s10339-017-0800-2.

Gocłowska, M. A., Baas, M., Crisp, R. J. and De Dreu, C. K. W. (2014). Whether social schema violations help or hurt creativity depends on need for structure, Pers. Soc. Psychol. Bull. 40, 959-971. doi: 10.1177/0146167214533132.

Goodman, N. (1976). Languages of Art: An Approach to a Theory of Symbols, 2nd ed. Hackett Publishing Company, Indianapolis, IN, USA.

Guilford, J. P. (1967). The Nature of Human Intelligence. McGraw-Hill, New York, NY, USA.

Kant, I. (2000 [orig. 1790]). Critique of the Power of Judgment, transl. P. Guyer and E. Matthews. Cambridge University Press, Cambridge, UK.

Kumkuoğlu, D. and Savaş, S.B. (2016). Temporal Perspectives. Istanbul. Available at: https:// www.dorukkumkumoglu.com/temporal-perspectives/.

Leder, H. and Nadal, M. (2014). Ten years of a model of aesthetic appreciation and aesthetic judgments: The aesthetic episode - Developments and challenges in empirical aesthetics, Br. J. Psychol. 105, 443-464. doi: 10.1111/bjop.12084.

Leder, H., Gerger, G., Dressler, S. G. and Schabmann, A. (2012). How art is appreciated. Psychol. Aesthet. Creat. Arts 6, 2-10. doi: 10.1037/a0026396.

Mastandrea, S., Fagioli, S. and Biasi, V. (2019). Art and psychological well-being: linking the brain to the aesthetic emotion, Front. Psychol. 10, 739. doi: 10.3389/fpsyg.2019.00739.

Maujean, A. Pepping, C. A. and Kendall, E. (2014). A systematic review of randomized controlled studies of art therapy, J. Am. Art Ther. Assoc. 31, 37-44. doi: 10.

Menninghaus, W., Wagner, V., Wassiliwizky, E., Schindler, I., Hanich, J., Jacobsen, T. and Koelsch, S. (2019). What are aesthetic emotions? Psychol. Rev. 126, 171-195. doi: 10.1037/ rev0000135.

Milk, C. (2012). The Treachery of Sanctuary. Available at: http://milk.co/treachery.

Muth, C., Hesslinger, V. M. and Carbon, C.-C. (2015). The appeal of challenge in the perception of art: How ambiguity, solvability of ambiguity, and the opportunity for insight affect appreciation, Psychol. Aesthet. Creat. Arts 9, 206-216. doi: 10.1037/a0038814.

Pelowski, M., Markey, P.S., Forster, M., Gerger, G. and Leder, H. (2017) Move me, astonish me... delight my eyes and brain: The Vienna Integrated Model of top-down and bottom-up processes in Art Perception (VIMAP) and corresponding affective, evaluative, and neurophysiological correlates, Phys. Life Rev. 21, 80-125. doi: 10.1016/j.plrev.2017.02.003. 
Pelowski, M., Leder, H., Mitschke, V., Specker, E., Gerger, G., Tinio, P. P. L., Vaporova, E., Bieg, T. and Husslein-Arco, A. (2018). Capturing aesthetic experiences with installation art: an empirical assessment of emotion, evaluations, and mobile eye tracking in Olafur Eliasson's “Baroque, Baroque!” Front. Psychol. 9, 1255. doi: 10.3389/fpsyg.2018.01255.

Pihko, E., Virtanen, A., Saarinen, V.-M., Pannasch, S., Hirvenkari, L., Tossavainen,T., Haapala, A. and Hari, R. (2011). Experiencing art: the influence of expertise and painting abstraction level, Front. Hum. Neurosci. 5, 94. doi: 10.3389/fnhum.2011.00094.

Ritter, S. M., Damian, R. I., Simonton, D. K., van Baaren, R. B., Strick, M., Derks, J. and Dijksterhuis, A. (2012). Diversifying experiences enhance cognitive flexibility, J. Exp. Soc. Psychol. 48, 961-964. doi: 10.1016/j.jesp.2012.02.009.

Ritter, S. M., Kühn, S., Müller, B. C. N., van Baaren, R.B., Brass, M. and Dijksterhuis, A. (2014) The creative brain: corepresenting schema violations enhances TPJ activity and boosts cognitive flexibilitym Creat. Res. J. 26, 144-150. doi: 10.1080/10400419.2014.901061.

Robinson, C. J. and Altarriba, J. (2014). The interrelationship between emotion, cognition, and bilingualism, Yearb. Poznan Linguist. Meet. 1, 103-117. doi: 10.1515/yplm-2015-0006.

R Studio Team. (2018). Rstudio: Integrated Development Environment for R [Computer software manual]. Boston, MA. Retrieved from http://www.rstudio.com/.

Scherer, K. R. (2005). What are emotions? And how can they be measured? Soc. Sci. Inform. 44, 695-729. doi: 10.1177/0539018405058216.

Schindler, I., Hosoya, G., Menninghaus, W., Beermann, U., Wagner, V., Eid, M. and Scherer, K.R. (2017) Measuring aesthetic emotions: A review of the literature and a new assessment tool, PLoS ONE 12, e0178899. doi: 10.1371/journal.pone.0178899.

Silvia, P. J. (2005). Emotional responses to art: from collation and arousal to cognition and emotion, Rev. Gen. Psychol. 9, 342-357. doi: 10.1037/1089-2680.9.4.342.

Silvia, P. J., Winterstein, B. P., Willse, J. T., Barona, C. M., Cram, J. T., Hess, K. I., Martinez, J. L. and Richard, C. A. (2008). Assessing creativity with divergent thinking tasks: Exploring the reliability and validity of new subjective scoring methods, Psychol. Aesthet. Creat. Arts 2, 68-85. doi: 10.1037/1931-3896.2.2.68.

Skov, M. and Nadal, M. (2020). A farewell to art: aesthetics as a topic in psychology and neuroscience. Perspect. Psychol. Sci., 15, 630-642. doi: 10.1177/1745691619897963.

Specker, E., Tinio, P. P. L. and van Elk, M. (2017). Do you see what I see? An investigation of the aesthetic experience in the laboratory and museum, Psychol. Aesthet. Creat. Arts 11, 265-275. doi: 10.1037/aca0000107.

Specker, E., Forster, M., Brinkmann, H., Boddy, J., Pelowski, M., Rosenberg, R. and Leder, H. (2020). The Vienna Art Interest and Art Knowledge Questionnaire (VAIAK): A unified and validated measure of art interest and art knowledge, Psychol. Aesthet. Creat. Arts 14, 172 185. doi: 10.1037/aca0000205.

Spence, C., Parise, C. and Chen, Y.-C. (2012). The Colavita visual dominance effect. The Neural Bases of Multisensory Processes, ch. 27. Boca Raton, FL, USA: CRC Press/Taylor and Francis.

Szubielska, M., Imbir, K. and Szymańska, A. (2019). The influence of the physical context and knowledge of artworks on the aesthetic experience of interactive installations, Curr. Psychol. doi: 10.1007/s12144-019-00322-w. 
The Guild of Ambience (2017) 1 hour of Ambient Fantasy Music I Tranquil Atmospheric Ambience I Enchanted Lands. [Video]. Youtube. Retrieved from https://www.youtube.com/ watch? $\mathrm{v}=$ RQcLIm-s75U.

Tschacher, W., Greenwood, S., Kirchberg, V., Wintzerith, S., van den Berg, K. and Tröndle, M. (2012). Physiological correlates of aesthetic perception of artworks in a museum, Psychol. Aesthet. Creat. Arts 6, 96-103. doi: 10.1037/a0023845.

Uusitalo, L., Simola, J. and Kuisma, J. (2012). Consumer perception of abstract and representational visual art, Int. J. Arts Manag. 15, 30-41. 


\section{Appendix A}

Table 1. Answers to the open-ended question "What do you think the artwork meant" in the lab.

Interactive condition

(1) The artwork was very dynamic and as I moved the artwork changed. Maybe it symbolizes the impact someone can have.

(2) I think the artwork has to do something with perception of humans in art because some of the pictures involved human faces or parts of the human body, for example a hand.

(3) Not sure of its meaning, I mostly focused on its different colours and movements.

(4) The artwork responded to our movements, in the vertical lines that were displayed but also the colours that were in each vertical display, more specifically the amount of blue and red. The art was either of a woman or of shapes. The fact that the art was of a woman's body and that we controlled the art to a certain event made me think that the art work could be trying to turn our attention to different perspectives people could have on art, as it just matters where you are standing.

(5) I don't know. It has a very 90 s feel to it. so maybe it represented the 90 s?

(6) I think its quite hard to guess the meaning in such abstract art. In my mind it could be about anything: drugs, the rising social isolation in the modern age or love (for example).

(7) It felt as if it pushes you to be more curious, that maybe not everything looks as it seems. It had a bit of an erotic nuance to it. I could see closeness, bonding, intimacy, closure with oneself or a significant other.

(8) It is mysterious, like the girl did something she now regrets.

(9) If you step back, you could see the art clearer, so it is also in life, if you open your mind a little bit more you could see it in another perspective and think in a different way.

(10) I think it had to do something with being anonymous and hiding parts of oneself to others. And also about the relationship to oneself and one's body.

(11) That people have inner world, which is obscured from outside.

(12) It could be about the things we miss when we walk by or about how we influence our environment, at the beginning I was not aware that the artwork changed because of my presence but as I moved I could see the effect I had.

(13) It reminds me of city lights with all the colourful lights and patterns. I suppose it represents the blur of a city life with the woman serving as the subject of the artwork.

(14) It shows body awareness and moods of people by the two different colours red and blue combined in harmony being so different. We can be different and feel different but this harmony together.

(15) I think the women in the artwork is in a difficult situations. It felt upsetting to see her, like she was trying to hide or not show certain emotions.

(16) Maybe something with a silhouette and abstract forms.

(17) At first I thought it was about illusions involving colours since I saw a person locked behind something but couldn't be sure whether that was because of the light or not. I think the art was about feeling trapped and about a girl feeling targeted and trying to escape that feeling. I think it symbolised fear of oppression of someone who is currently free but is threatened by something in the future. 


\section{Interactive condition}

(18) The way of seeing things.

(19) Connection between art and computers and humans.

(20) Could mean anything to different viewers. I saw it as a photographer trying to capture the solitude of her photography process.

(21) I think the artwork was meant to surface subconscious thoughts, like forgotten memories. The impressionistic style allows for many interpretations, but is overall aesthetically very pleasing.

(22) It took me to a deeper ground, I wanted to explore, interactive, it was relaxing, it touched me.

(23) I have absolutely no idea. I am very bad at meanings of artworks.

(24) I think it tried to make you think about perspective. You have to put yourself in a position in which you can truly see what the artist created, which means you have to engage in the artwork by making yourself available to its meaning.

(25) Maybe a colourflow combined with a model.

(26) Looking at the effect of contrast as a viewpoint and how where you stand metaphorically and literally can impact your view of a whole thing.

Non-interactive

It was about my movement and which part of the artwork I paid attention to. I think it was showing different sides of the same "painting" when I moved. You can make things happen, just as long as you stay on the move and take action. There are many possible outcomes, depending on what you decide to do.

For me it was about people hiding their inner self, because I could not see the faces of the persons.

I think it was maybe about if you put in the action/effort, others will also give the effort back/reveal more about themselves.

Something uniquely personal to the experience of the artist.

Change your perception as to where you are in the room, maybe it means that you see something else every way you look at it, left, right, close or far away in real life to.

(36) I thought it had something to do with sadness/a sad mood, but the music on the background and the colours used were somewhat confusing

(37) The artwork showed how people can be unrecognizable, fade out. It also had a meaning as to how emotions can quickly change.

(38) I think the poses of the models and the lighting used transmitted a feeling of being trapped.

(39) That there are masks on us that we cannot see, or that someone is more interesting when the person isn't showing himself fully.

(40) It represented the textures and colours we encounter in our life.

(41) The images could be illustrating the warm and cold side of a woman. While both sides show similar colours, the blue were more dominant on the right and the reds more dominant on the left.

(42) My first thought was about the human made of glass (we have no privacy anymore because of the internet). 
Interactive condition

(43) The blurredness of the pictures of the person (for me, I saw it as the same person) behind the milky glass door resembled the feeling of not belonging or possibly being outcasted in a way. In a way isolated, but not necessarily always in a way that it would only give you bad feelings, rather also the feeling of disconnectedness, which to some extent sometimes can be relaxing. However, when the hands turned red I also felt some sort of a feeling of possible guilt that the person could gone through (as a metaphor for the hands being drenched red colour, which could mean something bad had happened which this person is trying to hide and therefore does not show oneself. Only with the back of the head, or behind a blurry glass.

(44) It appeared to be representing people's emotions, probably melancholy or depression; it could represent their minds or inner feelings.

(45) It perhaps had something to do with distance towards someone and just not being able to get to them in a meaningful way. You try to get closer, but never fully get there.

(46) I believe it was about the movements, textures and colours and how they all coexist.

(47) It was supposed to sublime the viewer and that you think about a deeper meaning.

(48) I think it's about oppressive human who one to escape from a mundane world to a higher dimension. The art might imply the dream that is buried deeply inside.

(49) A woman who needs help.

(50) I would mention it was like living geometric figures, somehow I found like a heart beat in the figures related with the human figure that was also displayed.

(51) One lady was depressed, she felt clam and cannot change anything with her life (what she doesn't like).

(52) I have no idea.

(53) Creating awareness.

(54) The artwork seemed to be about anonymity or a "forgotten" person in the sense that they would require help, but are nothing is done about it. From one perspective we seem to understand this person or get closer to them, but then suddenly we lose ground again and we are in square one again.

(55) I can only guess what it meant. I felt it left me wanting more, since the person who's silhouette was seen was never uncovered. The music added a suspense to it. The colours had both warm and cold feelings, with them and I did not know what exactly the art made me feel like. It was so clean, and sharp because of the forms and still I felt I wanted to know more. Like something was hidden from me.

(56) A girl how tried to get out of her own thoughts, but got sucked in it.

(57) I think it meant a combination of anger and sad based on the colours.

(58) I don't know. The turning to red hands of a women in bath made me thought of blood.

(59) How shapes interact with people.

(60) Some of the more abstract pictures made me fascinated and intrigued. I liked how the lighting and the colour were changing. It made me feel curious. The music in the background added a spooky vibe to the experience - it made me quite relaxed, yet attentive to what is going to happen next. One picture of the woman's neck made me feel a little sexual tension with the music in the background.

(61) The person who was pictures wanted to hide and not show too much of themselves. The different colours and textures created a mysterious vibe.

(62) I saw my own reflection. it was incomplete, hurt and trying to hide the pain. 


\section{Interactive condition}

(63) I have no idea. At all.

(64) Low self esteem of people or feel ashamed. She was turned with her back towards me and when she looked at me, she was covered by a milky glass.

(65) I saw eyes in almost everything, it explains how people view the world.

(66) I felt like someone was hurt by me and therefore tried to escape my presence.

(67) It was a representation of the importance of colour, shadow, opacity, etc. and perhaps means to show that things aren't always what they appear.

(68) I think the artwork meant something about being caged as a human being.

(69) I really don't know... It felt somewhat mysterious due to the blurred screens and never seeing a face directly, but also sad in a way because of the composition and the music.

(70) Blurred, fragmented and ever-changing nature of a human identity. 


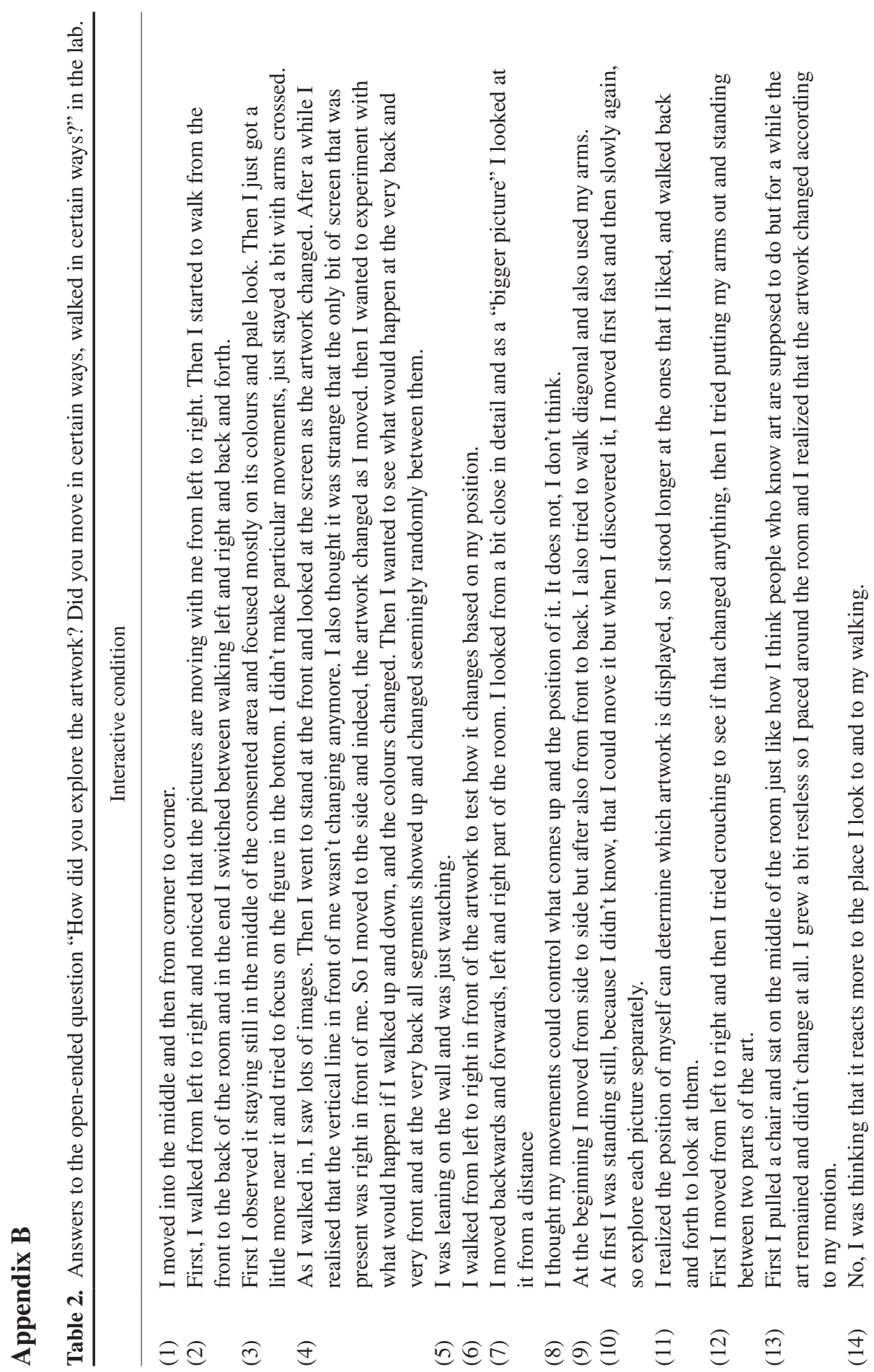




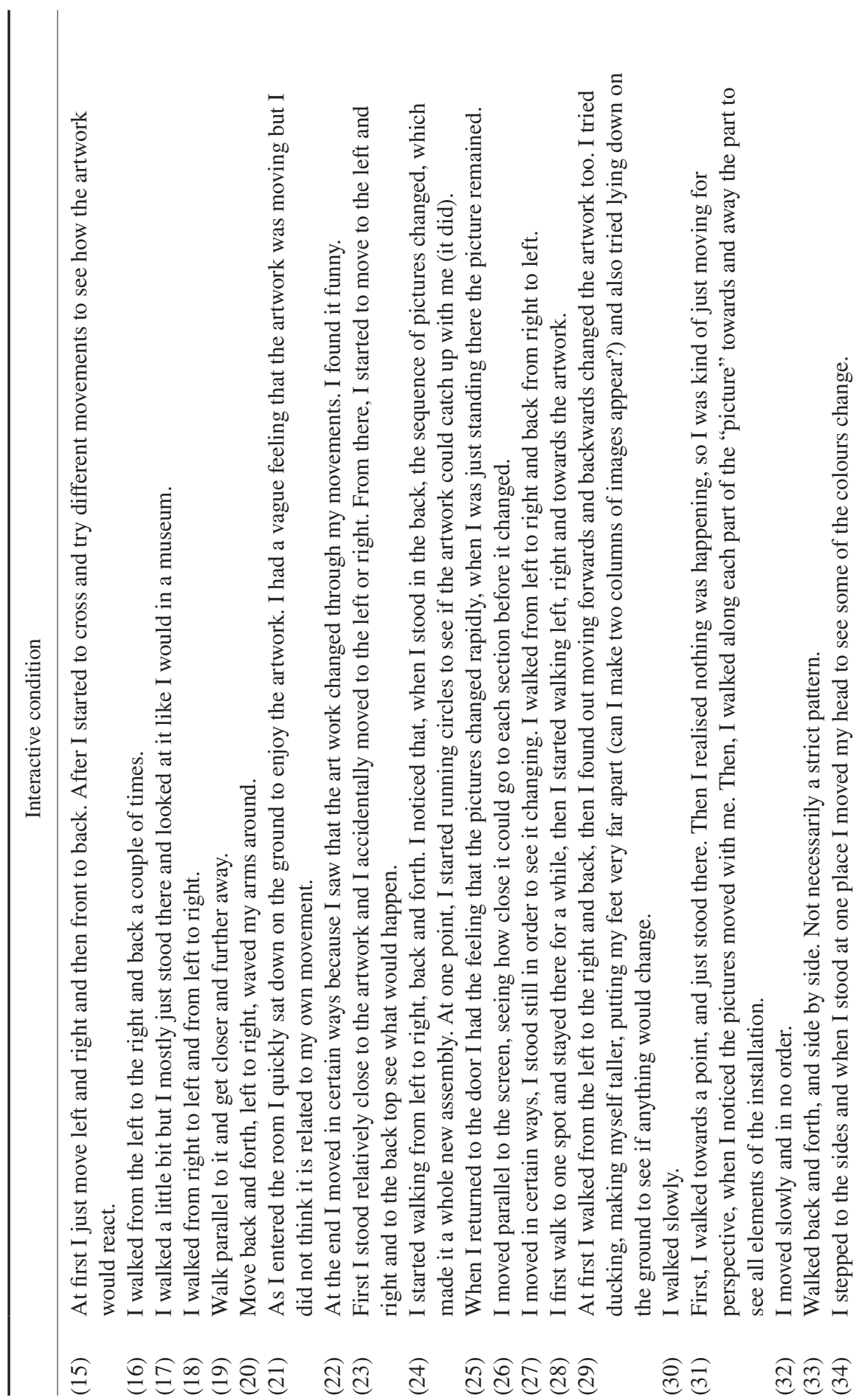




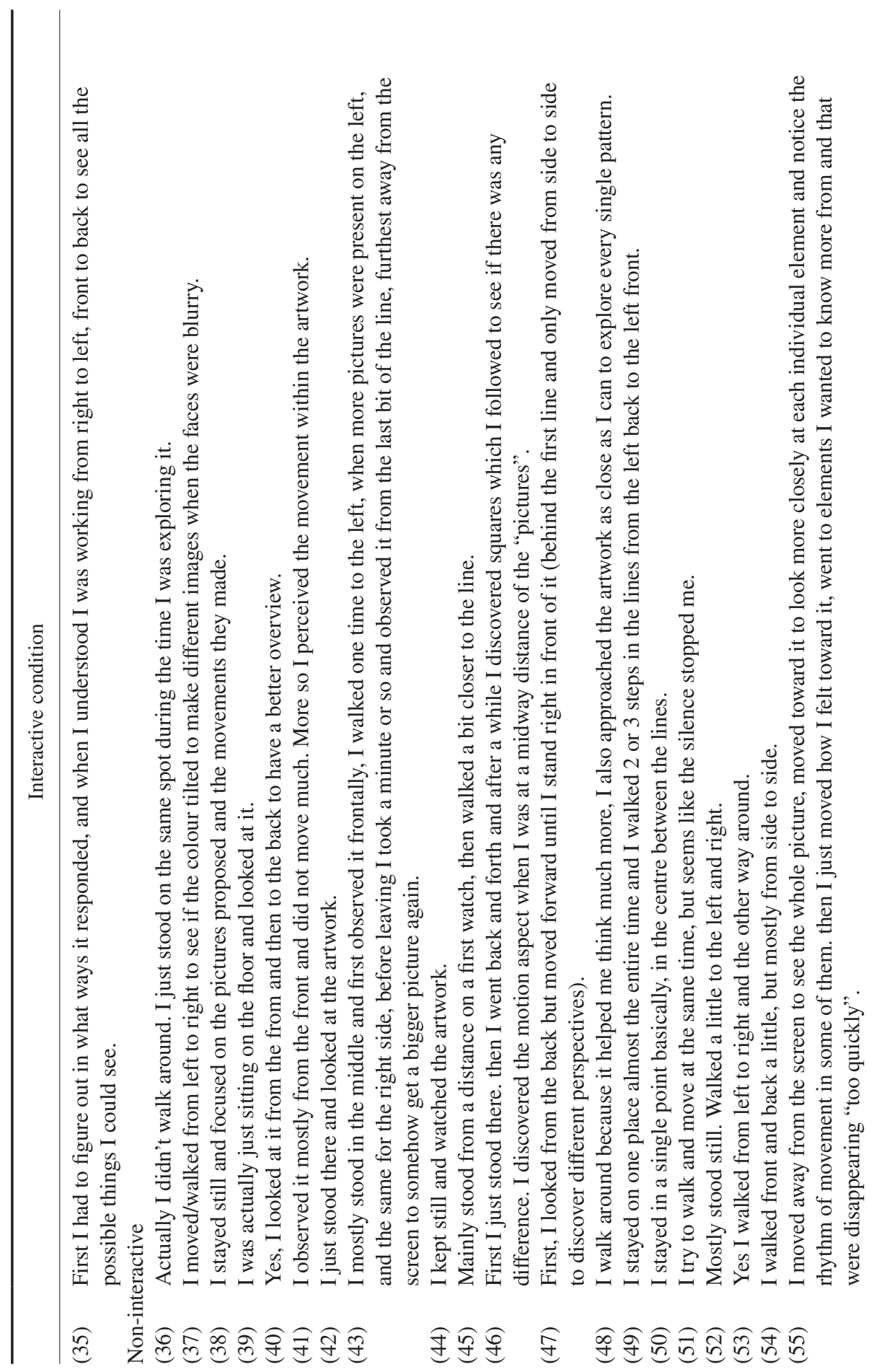




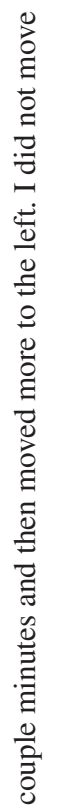

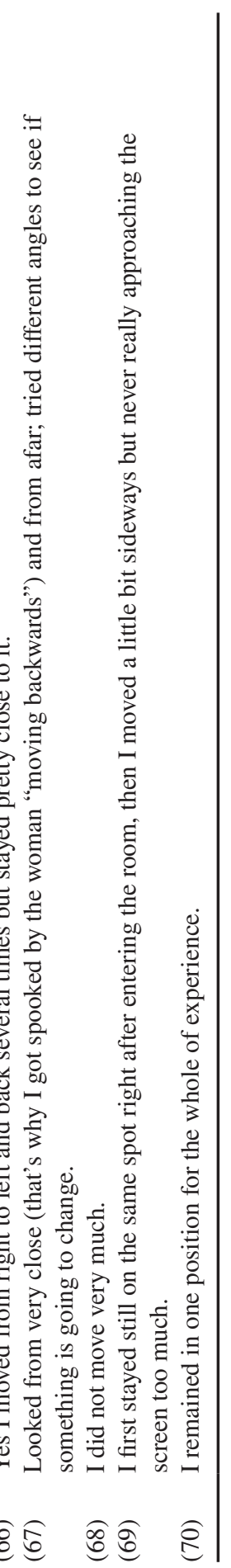

